\title{
DAS FRATURAS SOCIAIS E DOS PROCESSOS DE TRANSFORMAÇÃO: O LUGAR DO PATRIMÔNIO ${ }^{1}$
}

\author{
Ana Luiza Carvalho da Rocha \\ Cornelia Eckert
}

Nossa reflexão parte de nossa pesquisa antropológica na cidade e sobre o fenômeno urbano e as formas de sociabilidade, os estudos de memória coletiva, as trajetórias e a construção social da identidade dos habitantes, em particular de Porto Alegre, RS.

Os resultados dessa pesquisa são acessíveis pela internet no projeto que denominamos Museu Virtual da Cidade de Porto Alegre - Banco de Imagens e Efeitos Visuais, www.estacaoportoalegre.ufrgs.br .

\section{A memória coletiva pelo viés da vida metropolitana (mundo urbano moderno- contemporâneo)}

É notória a ausência de uma preocupação cultural e política com a memória no processo intelectual de pensar as sociedades ocidentais no bojo dos processos de colonização e industrialização.

Apenas na atualização dos paradigmas ocidentais de modernização, como nos estudos da Escola de Chicago, os primeiros a interessar-se pelo problema da desorganização, desestruturação e anomia acarretadas pela concentração das massas nas megalópoles contemporâneas, o tema da memória no contexto urbano emerge como tempo-espaço de reflexão.

A essa vertente de estudos e pesquisas sobre a cidade, responderam outros intelectuais formados nos quadros de uma sociologia européia e dedicados ao estudo do mundo urbano e dos problemas das relações capital/trabalho, lazer, individualismo, consumo, gosto, cotidiano, trajetórias e histórias de vida, em que se destaca a obra de Maurice Halbwachs que compõe a coletânea na versão francesa.

\footnotetext{
${ }^{1}$ Trabalho apresentado no Colóquio Patrimônio, Cidadania e Direitos Culturais, cidade de Goiás, 15 a 17 de junho/2006. Coordenadores Regina Maria do Rego Monteiro de Abreu/UNIRIO e Manuel Ferreira Lima Filho/UCG. RJ Local: Hotel Vilaboa - Cidade de Goiás (GO), 16 de junho de 2006 - 14h - Mesa Redonda Cidades Patrimoniais e Tesouros Humanos: por que e como preservar o passado? Coordenação: Manuel Ferreira Lima Filho no âmbito da $25^{\mathrm{a}}$ RBA, 11 a 14 de junho 2006.
} 
A recente emergência da memória como uma preocupação central nos estudos sobre a cidade moderna em sua condição de "criação destrutiva" (Nietzsche apud Harvey, 1992) desloca a constante insistência nos "futuros presentes" (Huyssen, 2000, p. 9) para o passado presente. Deslocamento esse que se refere a uma sensibilidade do tempo (em suas sobreposições e ritmicidades) nos fluxos das experiências de viver o cotidiano e no "jogar o social", citando Georg Simmel ao definir o que é a sociedade (Simmel, 1979).

$\mathrm{Na}$ aceleração do processo de recodificação do passado, os estudos sobre a cidade e suas transformações deslocam-se dos enfoques de estagnação e das utopias progressistas para um novo momento: o de viver a cidade como consciência de si, como realidade psíquica (Hillman, 1993, p. 12), na sua "destruição criativa" (Nietzsche apud Harvey, 1992). O tema da memória começa a considerar as liberações das determinações reticulares de um processo civilizatório, diz Norbert Elias (1994). Um exemplo disso é a recuperação recente dos estudos de memória e esquecimento, em Walter Benjamin, e de sociabilidade, em Georg Simmel, sobre a estética do viver urbano nas dinâmicas interativas das experiências sociais e sensíveis, o que significa refletir sobre a condição da vida na cidade.

Nessa perspectiva, estando as "coisas urbanas" restituídas à alma e sua realidade psíquica dada com anima mundi (Hillman, 1993), a cidade aparece em sua dimensão de interioridade e profundidade. A cidade presta testemunho de si mesma nas imagens pelas quais se oferece aos seus habitantes, e sua complexidade configura-se nas ações, nos pensamentos, nas mentes e nos corações da condição dos citadinos em suas trajetórias e memórias.

Se somos a cidade, a cidade é nosso contexto, como "o anel retroativo de Norbert Wiener", ou o fenômeno reticular em geral de Norbert Elias, ou a autopoiésis de Humberto Maturana ou o refinado paradigma hologramático de Edgar Morin.

Uma vez que "todos os circuitos informacionais da metrópole constituem parte integrante da minha "mente"”( ...) "eu sou a cidade na qual vivo" (Canevacci, 1993, p. $81)$.

Dessa forma, sou também a cidade que me contém, me abriga, que eu interpreto. Entende-se essa mensagem de diferentes formas, como um sistema comunicativo. Não reagimos a ela apenas psicologicamente (sem negligenciarmos aqui esse aspecto), mas comunicativamente, cultural, social e historicamente. Na cidade moderna, o lugar da 
preservação da matéria do tempo, os museus, são, portanto, lugares de memória e, assim, depositórios da identidade dos habitantes dessa cidade.

Mas, basta ser um lugar de memória?

Deveríamos começar, então, a pensar os "lugares da memória" (Le Goff, 1988), e, em destaque neste artigo, as cidades patrimoniais, os museus, os arquivos e os prédios históricos conservados tanto quanto as ruínas e as ambiências turísticas, áreas de proteção cultural, sob o invólucro das Sociedades Complexas, das formas de vida social no meio urbano e que mais recentemente tornam-se objeto de indagação aos olhos dos antropólogos sob o comentário atento de Georg Simmel: “A vida engloba em um só ato a limitação e o deslocamento do limite”. A ênfase analítica dá-se sobre as formas de organização e interação entre indivíduos e suas redes de relações como campos de negociação da realidade em múltiplos planos.

Nas modernas metrópoles, a vida humana torna-se objeto principal de estudo pelos "retalhos e pelos resíduos", "secundário ou excêntrico", isto é, a moda, o jogo, o colecionador, os dioramas, a prostituição, o flâneur, as passagens, o interior, as ruas, a fotografia, o réclame", tudo atribui sentido de lugar, de pertença a uma história urbana que também se esvai no tempo.

Em nome da sua perspectiva materialisticamente teológica, Walter Benjamin (1993) nos ensina que, na Cidade, o objeto da duração não é unicamente o presentefuturo, mas também o passado. Para Benjamin, a narrativa urbana, para durar no tempo, não necessita recorrer a recursos estilísticos "preciosos" para se configurar como memória e patrimônio. Ao contrário, ela precisa aderir à fluidez do tempo e à efemeridade dos processos de transformações dos sistemas de representações simbólicos (imagens e valores) que caracterizam a vida na cidade.

A vida urbana como objeto temporal pode ser interpretada, portanto, por suas "regiões morais" (Park, 1979) e suas "províncias de significado" (Schutz apud Wagner, 1973), sendo desvendadas a partir das falas que reconstroem os itinerários dos seus moradores.

Em nossa pesquisa no BIEV, a cidade moderna apresenta-se a partir da própria idéia de "negociação da realidade" (Berger\&Luckmann, 1983), tendo como ponto de partida não só o reconhecimento da diferença como elemento constitutivo das 
sociedades urbano-industriais, mas a condição particular da escritura etnográfica em diferentes suportes (fotografia, vídeo, registro sonoro, escrita, etc) em face de sua tradição de origem.

A cidade assume, assim, um lugar estratégico como locus privilegiado para a reflexão antropológica sobre a "comunicação" que preside as formas de vida social no meio urbano e sobre as multiplicidades e as singularidades que encerram o vivido humano no interior desse espaço existencial criado pelo homem da civilização.

Eis por que se torna aqui interessante pontuar o lugar estratégico que hoje ocupa, para nós do BIEV, o estudo dos itinerários dos grupos e/ou indivíduos e de suas formas de sociabilidade na compreensão do mundo urbano contemporâneo.

O deslocamento dos grupos/indivíduos entre as "províncias" e os "territórios" de significação nas cidades é uma das questões cruciais para se compreender o fenômeno da memória coletiva e, por consequiência, da estética urbana das modernas sociedades urbano-industriais, tornando-se, sob esse ângulo, um elemento perturbador para se repensar a questão patrimonial.

É por meio do estudo dos fluxos desses itinerários urbanos e das formas de sociabilidade, das intrigas e dos dramas que configuram o teatro da vida citadina, apreendidos como uma espécie de mapeamento simbólico do movimento da vida humana, que se pode, nos dias de hoje, refletir sobre a complexidade sociológica das estruturas espaço-temporais sob as quais se assenta o fenômeno do patrimônio humano no mundo contemporâneo.

Reconhece-se, assim, que o fenômeno urbano é o resultado da ação recíproca de indivíduos e de grupos no plano de trocas sociais.

Com isso, desponta a importância, para a Antropologia, do estudo das formas específicas dos arranjos da vida social na cidade segundo a complexidade dos gestos acumulados de seus habitantes, seja para a compreensão do processo de territorialização/desterritorialização de identidades sociais no mundo contemporâneo; seja para o entendimento da descontinuidade/continuidade sistêmica de valores acionados por esses habitantes, ou ainda para a compreensão de redes/espaços sociais onde se situam tais habitantes segundo suas trajetórias, posições e papéis, suas adesões e suas dissidências a certos lugares do contexto citadino.

No que tange à adequação/transformação entre forma social e fluxo vital e entre (instituições e comportamentos individuais e coletivos, vistos sob o ângulo da transformação mundial das culturas, é por meio da incorporação da Diferença que se 
pode elucidar o papel de políticas públicas no campo patrimonial no mundo urbano contemporâneo.

Nas últimas décadas, no plano dos saberes e fazeres das ciências humanas, a compreensão da Diferença tem desafiado o pensamento antropológico em suas bases epistemológicas, interrogando-o nos termos do conteúdo ético-moral de seus postulados universalistas. Isso tem conseqüências para o tratamento conceitual do que se pode pensar como "cidades patrimoniais": por exemplo, qual o lugar que ocupa a desordem no campo das políticas públicas na área patrimonial, por vezes asfixiado pela obsessão de encontrar "leis absolutamente necessárias e universais" para vida social

A destruição/reconstrução de singularidades culturais e regularidades locais nas megalópoles contemporâneas cada vez mais remete o antropólogo a pensar as referências de tempos vividos e ordenados na experiência ordinária dos atores sociais como forma de atribuir significação aos seus atos/pensamentos.

Na cidade, a Antropologia não busca mais o Outro como algo fixo, estranho. Não há posição de exterioridade, assim como não há identidades estáveis nem localizações fixas. Há apenas deslocamentos e fluxos. A cidade é o contexto vivido com a pluralidade de alteridades, com aquele que eu não conheço, mas que não é excluído.

Da fragmentação, heterogeneidade de regiões morais e descontinuidades de universos simbólicos às situações de crise: violência, catástrofes, mortes

Para se pensar o tema das cidades patrimoniais e dos tesouros humanos (por que e como preservar o passado?) precisamos, em primeiro lugar, saber de que cidade estamos falando, para depois relacionar tais tesouros ao tema das identidades sociais.

A crítica ao processo de construção de museus e aos processos de patrimonialização no mundo contemporâneo confunde-se com a intensa desconfiança epistemológica ou ética da Antropologia com relação aos discursos universais ou totalizantes. Epistemologicamente, acompanha a revisão crítica das ciências humanas com base na crise de paradigmas apontada por autores da área da filosofia da ciência, tais como a de Thomas Kuhn (apud Geertz, 2001) e Gaston Bachelard (1996), os trabalhos de Michel Foucault (2001) sobre a arqueologia do saber, entre outros, e a abordagem da descontinuidade e da diferença na história.

Richard Sennet $(1994,1998)$ diz que o que faz a cidade ser cidade consiste justamente numa forma de tolerância para com o estranho, mas, para isso, pressupõe 
que os cidadãos aceitem a sua cidade como sua própria civitas, como um contexto próprio de vida. Mas essa aceitação pode facilmente desagregar; vivemos e conhecemos essa tensão criada pela violência, pela criminalidade, pela discriminação, pela exclusão, pelo desrespeito ao Outro constante, em que a ausência de reciprocidade é a anticidade. Assim, preservar a matéria no tempo, o patrimônio, não pode estar descolado do trabalho de gerar sentido aos diferentes grupos sociais da dialética da duração dos lugares depositórios da memória coletiva.

\section{A indeterminação e a intensa desconfiança à face das situações de crise social}

A questão patrimonial, hoje, constrói uma condição privilegiada para o fazer antropológico. E aqui, sobretudo, introduzimos a estratégia de produzir conhecimento sobre a condição urbana e o papel da análise da memória dos habitantes na cidade no contexto atual, onde política e ciência dialogam para promover as "identidades narrativas" (Ricoeur, 2000), as quais detêm a capacidade de subverter a idealização da linearização do tempo.

Por meio de debate em torno das políticas de patrimonialização, a Antropologia passa a refletir sobre os sentidos dos lugares urbanos - do sentido do "público" para os territórios da vida social nas grandes cidades - como experiências de habitá-los.

Assim é que as ações patrimoniais levadas a cabo pelas políticas culturais dos diferentes países abarcam questões sobre o ato interpretativo que as fundamenta, desdobrando-se em debates sobre os princípios éticos de cidadania, de direitos humanos e de respeito à diferença.

Os chamados Outros hoje constroem seus próprios projetos autorais, buscando, inclusive, o repatriamento de seus objetos sagrados, até o momento guardados em museus e arquivos, nas nossas sociedades ocidentais, como nos sugere Bárbara Glowczewski em seus recentes estudos junto aos povos aborígines australianos (2000).

Trata-se de conhecer o movimento social em termos de questões éticas, e não só de política, pois somente o debate acerca da ética pode definir os limites que a política cultural não terá o direito de ultrapassar. Nesse sentido, fica cada vez mais evidente que, nos termos de uma cidade patrimonial, pertencer à humanidade não nos dispensa de pertencer a uma nação, entretanto, a segunda não pode substituir a primeira uma vez que é a humanidade que deve poder conter a razão do Estado.

Do ponto de vista de uma cidade patrimonial, essa precisa estar apta a oferecer um 
leque de interpretações para que os seus diferentes habitantes ou visitantes nela se reconheçam como parte de uma comunidade cultural e de uma sociedade humana. Para tanto, o tema da ética é aqui central desde que derive para o exercício da reflexividade, o que implica a possibilidade de os habitantes poderem se representar nas políticas públicas dirigidas à área de patrimônio cultural no interior das sociedades complexas. Anthony Giddens $(1990,1994)$ adentra o tema da confiança tratada no âmbito da teoria do risco e à modernidade reflexiva, almejando contemplar os múltiplos dispositivos para se lidar com a liberdade de interpretação e de reciprocidade cognitiva entre o habitante e as instituições que o representam.

A condição principal de requisitos para a confiança dos habitantes nas formas de viver de sua cidade, sendo essa um território de pertença, seja ela qual for, não reside, apenas, na falta de poder ou no abuso do poder dos poderes públicos em disponibilizar a esses habitantes seus equipamentos urbanos. A confiança dos habitantes em sua cidade depende da "circularidade dos sentidos" (Bakhtin, 1993) produzidos nas diferentes ações destrutivas e criativas (Nietzsche apud Harvey, 1992), que transformam ou preservam os espaços que eles almejam, de lugares de referência identitária onde possam produzir formas interativas de viver uma trajetória coletiva e de narrativas intra e intergeracionais, onde reside a importância da informação democrática.

Os lugares da memória, como os museus, assim como quaisquer outras instituições modernas, situam-se nesse contexto sistemático de suspeitar de sua própria condição conceitual, da eficácia do patrimônio edificado tanto quanto do tombamento da memória coletiva em orientar para conhecimento das práticas que tecem as instituições modernas.

Os desencaixes no espaço-tempo como condição da vida moderna não podem nos encerrar na tragédia de conceber as políticas patrimoniais como atos de cimentação de uma continuidade dos sentidos da cultura contra os perigos do esquecimento.

Para nós, aqui, é evidente a relevância do fazer antropológico na área patrimonial como espaço de construção de uma interpretação dos sentidos de continuidade de uma sociedade, isto é, de esse saber-fazer gerar narrativas que produzam fóruns de conhecimento entre seus habitantes e em que haja consciência de que a atividade humana é criada socialmente e não dada pela natureza das coisas. O que deve durar é o que tem sentido afetivo na trajetória dos grupos sociais, o que reverbera, diz Gaston Bachelard (1990), e produz um excedente de sentidos, como afirma Paul Ricoeur (2000).

Tendo em vista o dinamismo das práticas sociais no mundo urbano 
contemporâneo, torna-se necessário se pensar as políticas patrimoniais associadas às fronteiras simbólicas onde se encerram as práticas dos grupos e/ou indivíduos. Nesse sentido, a identidade, no contexto atual, não pode ser promovida nos projetos culturais patrimoniais senão marcados pela tensão do reconhecimento das alteridades, dos direitos humanos tanto quanto da trajetória e liberdade individual a partir da confiança nas instituições que se querem como promotoras de eventos de reflexão das informações renovadas sobre as práticas sociais, individuais e coletivas.

Aqui referimos novamente nosso projeto de museu virtual, no caso do trabalho de pesquisa que desenvolvemos no BIEV, como provocando os trabalhos de memórias coletivas por meio de jogos interpretativos de reconhecimento de seus habitantes e de conhecimento de si mesmos como um outro, pela via de uma identidade narrativa.

\section{Cidade e suas crises, o patrimônio pelo viés da memória: Porque e como preservar o passado?}

Com tudo o que vimos afirmando, queremos ressaltar que, em um quadro de transformação e de crise, característico do mundo contemporâneo, a memória coletiva é fundamental para o sentimento de continuidade do corpo coletivo de uma comunidade urbana no interior das grandes cidades, disso resultando as formas de vida social na cidade como depositárias de sentido para os habitantes.

No Brasil, uma das principais contradições que marcam a paisagem dos seus grandes centros urbanos é a expansão da cidadania política em face da deslegitimação da cidadania civil, e, nesse contexto, as políticas patrimoniais podem e devem ocupar espaços significativos de distribuição de poderes e saberes nas formas de ocupação da cidade e de produção de sentido para as práticas sociais que aí transcorrem.

Aqui cabe perguntar: Qual a importância do exercício de memória na construção do sentido do "público" no desenho das práticas sociais urbanas e como o museu e as políticas públicas patrimoniais devem agir em relação à cidade? Aristóteles já dizia que os extremos precisam desaparecer, e o mais perigoso dos extremos em uma polis é um número excessivo de pobres ao lado de um número pequeno de ricos. O perigo mora no desinteresse pelo bem-estar da polis, por um projeto de troca na condição urbana.

No Brasil, nas últimas décadas, assistimos a uma expansão real da cidadania política, por outro lado, assistimos igualmente à expansão do universo do crime. Um dos mais intrigantes fatos da consolidação democrática brasileira é o de que a violência, tanto civil quanto de aparatos do Estado, aumentou consideravelmente desde o fim do 
regime militar. Esse aumento no crime e na violência está associado à falência do sistema judiciário, à privatização da justiça, aos abusos da política, à fortificação das cidades e à destruição dos espaços públicos.

Como sugerem os pesquisadores que têm se preocupado com o tema, como Tereza Caldeira e Alba Zaluar, no Brasil a democracia política não trouxe consigo o respeito pelos direitos, pela justiça e pela vida humana, mas, sim, exatamente os seus opostos. Nesse contexto, o crime não só expressa e articula outros processos negativos de mudança, como também representa os limites e desafios da democratização brasileira.

O universo do crime indica o caráter disjuntivo da democracia brasileira (Caldeira, 2003) por duas razões: em primeiro lugar, porque o crescimento da violência em si deteriora os direitos dos cidadãos e, em segundo, porque ele oferece um campo fecundo, no interior do qual as reações à violência tornam-se não apenas violentas e desrespeitadoras dos direitos, mas ajudam a deteriorar o espaço público, a segregar grupos sociais e a desestabilizar o estado de direito.

Qual o sentido de falarmos de cidades patrimoniais no quadro atual?

No contexto aqui descrito, a cidade transparece como espaço onde os jogos da memória e do esquecimento atravessam questões de ressentimentos, de mortes e de vitimização que mergulham a todos em um forte sentimento de crise em face da criminalidade nas cidades. Essas situações de crise não devem ser negligenciadas no processo de negociar com os fenômenos da memória, sem, entretanto, orientar a memória como povoada pelo abuso da tragédia sem perceber, na crise, a própria força de transformação e o perigo de cair na armadilha do despotismo do esquecimento dessas situações paroxísticas.

\section{As memórias coletivas e as identidades sociais}

À guisa de conclusão, a cidade é, estudo, um lugar de pertença, não apenas um assunto do ser individual, pessoal, de cada um de nós. Ela precisa ser vivida no mundo, num diálogo com outros. O nosso eu interior descobre seu lugar no mundo ao participar da identidade de uma coletividade. Toda identidade é concretizada por meio da participação na cultura.

Os conceitos de construção de identidade e de cultura nasceram juntos e é por isso que toda identidade cultural anda de mãos dadas com a política cultural. Toda nação deve ser independente numa sociedade multicultural; as diferenças culturais devem ser 
respeitadas e até mesmo estimuladas sem deixar de dialogar com a ciência. Retomando o que dizemos mais acima sobre a relação entre política e ciência, recorremos a Gilbert Durand (1988) que, baseado em Bachelard e Freud, nos alerta de que uma ciência sem consciência, sem reconhecimento de seus erros e de sua trajetória e sem afirmação mítica de uma esperança marca o declínio definitivo de nossas civilizações. E isso extensivamente para as políticas patrimoniais.

Não podemos separar a memória do projeto de desejar, criar, transformar e, portanto, construir uma duração para a vida social. Somos sempre as recapitulações de nós mesmos, ou seja, somos o resultado da nossa vontade de fazer sentido com tudo o que nos aconteceu; somos a projeção dessas intenções, dessas expectativas, das antecipações, mas também dos atos de vontade que são sempre os projetos, das coisas a fazer.

Esse é o grande desafio que os projetos patrimoniais devem se colocar hoje.

O que fazer? A tarefa é cultural e envolve a comunidade e o fato de ela ter interesse por um projeto de ser cidade. Da preocupação com a estética à eliminação da injustiça social, o importante é criar espaços e tempos de refletir sobre a cidade. E aqui os lugares da memória (prédios preservados, museus juntos com as universidades) têm um papel essencial.

Sem medo de espetacularizar a cultura ou banalizar a prática científica, nossas ações de pesquisa no BIEV têm se orientado por tratar esses processos da cultura urbana como dinâmicas de interpretação plural e diversa de um olhar sobre as formas diferentes de habitar a cidade, uma leitura estimulada na interação da própria cena urbana.

Uma exposição na rua, o uso de novas tecnologias, uma oficina, um colóquio, uma mostra, uma instalação, um evento, uma interação, a escuta do antropólogo, a sua interpretação, o seu retorno à comunidade podem colocar a cidade como núcleo potencializador de criatividade, de transformações e de espaço de negociações de realidade culturais.

Nesse sentido, pensamos que talvez o papel das cidades patrimoniais no Brasil, hoje, não seja só o de garantir objetivamente qual é a cidade que se quer como ideal, mas de permitir aos seus habitantes, seus visitantes e passantes sonhar a cidade, poetizar, mitificar, fabular, para instaurar a liberdade remitificante de ver, na tensão entre passado e presente, a possibilidade de participar de forma efetiva do projeto de humanização do trajeto da humanidade. 


\section{REFERÊNCIAS}

BACHELARD, Gaston. A dialética da duração. PUF, Paris, 1989.

BACHELARD, Gaston. A formação do espírito científico: contribuição para uma psicanálise do conhecimento. Rio de Janeiro, Contraponto, 1996.

BACHELARD, Gaston. A terra e os devaneios do repouso. Ensaio sobre as imagens da intimidade. São Paulo, Martins Fontes, 1990.

BAKHTIN, Mikhail. A cultura popular na Idade Média e no Renascimento. $O$ contexto de Francois

Rabelais. São Paulo e Brasília, Edunb e Hucitec, 1993.

BARNOW, E. El documental, historia y estilo, Barcelona, GEDISA, 1996.

BENJAMIN, Walter. "O narrador. Considerações sobre a obra de Nikolai Leskov" In: Magia e técnica, arte e política. Ensaios sobre Literatura e História da Cultura. São Paulo, Brasiliense, 1993.

BENJAMIN, Walter. "Walter Benjamin". Coleção Grandes Cientistas Sociais. São Paulo, Ática, 1991. BERGER, Peter I. et LUCKMANNN, Thomas. A construção social da realidade. Petrópolis, Vozes, 1983.

BOURDIEU, Pierre. La distinction: critique sociale du jugement. Paris, Ed. de Minuit, 1979. CALDEIRA, Tereza P. A cidade de muros. São Paulo, Edusp, Ed 34, 2003.

CANEVACCI, Massimo. A cidade polifônica. São Paulo, Studio Nobel, 1993. DURAND, Gilbert. A imaginação simbólica. São Paulo, Cultrix, 1988.

ELIAS, Norbert. A sociedade dos indivíduos. Rio de Janeiro, Jorge Zahar Editor, 1990. FOUCAULT, Michel. Arqueologia do Saber. São Paulo, Forense Universitária, 2001. GEERTZ, Clifford. Nova luz sobre a Antropologia. Rio de Janeiro, Jorge Zahar, 2001.

GIDDENS, Anthony et alli. Reflexive Modernization. Politics, Tradition and Aesthetics in the Modern Social Order. Cambridge : Polity Press, 1994.

GIDDENS, Anthony. The Consequences of Modernity. Cambridge: Polity Press. 1990. GLOWCZEWSKI, Barbara. «Au nom du père et de la terre. Les Aborigènes aux prises avec le passé ", L'Homme, 154-155 - Question de parenté, 2000 http://homme.revues.org/document $40 . h t m l$

HALBWACHS, Maurice. "Chicago, expérience ethnique". In: L'Ecole de Chicago Naissance de l'écologie urbaine. Textes traduits et présentés par Yves Grafmeyer et Isaac Joseph. Paris, RES Champ urbain, Aubier, 1979.

HALBWACHS, Maurice. A memória coletiva. São Paulo: Vértice, 1990.

HARVEY, David. Condição Pós-Moderna. São Paulo, Edições Loyola, 1992.

HILLMAN, James. Cidade \& Alma. São Paulo, Studio Novel, 1993.

HUYSSEN, Andreas. Seduzidos pela memória. Rio de Janeiro, Aeroplano, 2000.

LE GOFF, Jacques. Histoire et mémoire. Paris, Foli Histoire, Gallimar, 1988.

MATURANA, Humberto e VARELA, Francisco. El árbol del conocimiento. Santiago do Chile, Editorial Universitaria, 1984.

MORAES FILHO, E. (Org.). Simmel. São Paulo, Editora Ática, 1988. MORIN, Edgar. La complejidad humana.aris, Flammarion, 1994.

MORIN, Edgar. Método (1. La Naturaleza de la naturaleza, 2. La Vida de la vida, 3. El Conocimiento del conocimiento, 4. Las Ideas, su hábitat, su vida, sus costumbres, su organización). Paris, Senil, 1999. MORIN, Edgar. Une politique de civilisation, con Sami Naïr, Paris, Arléa, 1997.

PARK, Robert Ezra. "La ville, propositions de recherche sur lê comportement humain em milieu urbain",

"La ville comme laboratoire social", "La ville, phénomène naturel ». In : L'Ecole de Chicago Naissance de l'écologie urbaine. Textes traduits et présentés par Yves Grafmeyer et Isaac Joseph. Paris, RES Champ urbain, Aubier, 1979.

RICOEUR, Paul. La mémoire, l'histoire, l'oubli. Paris, Seuil, 2000.

RICOEUR, Paul. Teoría de la interpretación, discurso y excedente de sentido. Madrid, Siglo Veintiuno Editores, Universidad Iberoamericana, 2000.

SENNET, Richard. O corpo e a cidade na civilização ocidental. São Paulo, Record, 1994.

SENNET, Richard. O Declínio do Homem Público. São Paulo, Cia das Letras, 1998.

SIMMEL, Georg. A metrópole e a vida mental. In: VELHO, Otávio G. (org). O fenômeno urbano. Rio de Janeiro, Zahar, 1979.

WAGNER, Helmut R. (Org. e Introdução). Fenomenologia e relações sociais. Textos escolhidos de Alfred Schutz. RJ, Zahar, 1979.

ZALUAR, Alba. Condomínio do diabo. Rio de Janeiro, Revan e UFRJ, 1994. 
ZALUAR, Alba. Medo do crime, medo do diabo. Unicamp/IMS-UERJ, 1994. 